\title{
Mecatrônica Educacional Apoiando o Aprendizado de Conceitos de Física e Matemática: Um estudo de caso
}

\author{
Charles Soares Pimentel $^{1,2}$, Kate Revoredo ${ }^{3}$, Fábio Ferrentini Sampaio ${ }^{4}$ \\ ${ }^{1}$ Aluno do curso de Especialização da Pós-Graduação em Tecnologias da Informação \\ Aplicadas à Educação (PGTIAE - NCE/UFRJ) \\ ${ }^{2}$ Professor de Matemática e Robótica da Escola Modelar Cambaúba, Ilha do \\ Governador - Rio de Janeiro, RJ \\ ${ }^{3}$ Departamento de Informática Aplicada (DIA - CCET/UNIRIO) \\ ${ }^{4}$ Programa de Pós-Graduação em Informática (PPGI/UFRJ)
}

\begin{abstract}
This paper deals with the application of Problem-Based Learning methodology in the context of Educational Mechatronics as a catalyst agent of the student's motivation in studying concepts of physics and mathematics. A case study with students of 1st year of high school was conducted to evaluate the proposed approach.
\end{abstract}

Resumo. Este trabalho trata sobre a aplicação da metodologia de Aprendizagem Baseada em Problemas no contexto da Mecatrônica Educacional como agente impulsionador da motivação do educando em estudar conceitos de física e matemática. Um estudo de caso com alunos do $1^{\circ}$ ano de ensino médio foi conduzido para avaliar a abordagem proposta.

\section{Introdução}

Atualmente a maneira como a maioria das salas de aula têm sido conduzidas é motivo de inquietação por parte de educadores preocupados com a falta de motivação dos alunos do século XXI. O desinteresse pelas aulas expositivas e unidirecionais, onde o professor é o detentor e expositor do conhecimento (e o aluno o receptor), tem sido a causa de atrito entre docentes e discentes que enxergam a realidade educacional de maneiras distintas.

Neste contexto as tecnologias de informação e comunicação (TIC) são importantes aliados na melhoria do proceso de ensino-aprendizagem, buscando uma maior aproximação do aluno com a escola. Contudo, ainda existem lacunas sobre como aplicá-las.

Uma área tecnológica que tem sido amplamente divulgada pela mídia, e tem servido de aliado para potencializar as aulas, é a Mecatrônica.

A Mecatrônica configura-se numa área que utiliza as tecnologias de mecânica, eletrônica e a tecnologia da informação para fornecer produtos, sistemas e processos 
melhorados, constituindo-se numa das áreas mais novas da engenharia, bem como no nível técnico-profissionalizante, em todo o mundo (Rosário, 2005).

Quando se fala neste recurso, professores ficam motivados com a possibilidade de se ter um novo caminho para lecionar e apresentar aos seus alunos conceitos, como por exemplo, os de matemática e física, através de uma estratégia diferenciada. O comprometimento do educando durante a construção do projeto de ME é fundamental para o avanço da utilização desta ferramenta como instrumento educacional o que gera, no primeiro momento, o seguinte questionamento por parte dos educadores: "Como motivar o meu aluno a se envolver nesta nova proposta?".

Uma possível dificuldade inicial em envolver o educando na proposta pedagógica pode desestimular o professor que, em alguns casos, desiste de continuar trabalhando com esta ferramenta. Se o educador apresentar o seu projeto, sem uma estratégia que seja motivadora, o que poderia ser um importante momento de aprendizagem, se torna apenas um momento de diversão.

Desta forma, este artigo procura contribuir com este debate, apresentando um trabalho em desenvolvimento numa escola particular do Rio de Janeiro, onde utiliza-se a mecatrônica como instrumento integrador de conceitos abordados em diferentes disciplinas do currículo escolar. Assim, na seção 2, apresentamos a fundamentação teórica que sustenta a proposta. Na seção 3 é apresentado o projeto proposto como problema. A seção 4 trata da avaliação da aprendizagem durante o trabalho com mecatrônica e por fim, na seção 5, apresentamos as conclusões e apontamos para alguns trabalhos futuros.

\section{Fundamentação Teórica}

Nesta seção os conceitos de Mecatrônica Educacional e Aprendizagem Baseada em Problemas serão apresentados.

\subsection{A Mecatrônica Educacional}

A Mecatrônica Educacional envolve a construção de projetos a partir do uso de sucatas e materiais elétrico-eletrônicos. Assim, um projeto de ME inclui o trabalho com partes mecânicas tais como marcenaria, soldagem, utilização de ferragens e afins, bem como conhecimentos básicos de eletrônica e programação de computador. Dessa forma, o aluno percebe que conceitos de matemática tais como geometria plana e espacial, e de física, como eletricidade, aprendidos na educação básica, são de fundamental importância para o sucesso do trabalho. Além disso, toda a criação gera no aluno uma sensação de importância no que se está trabalhando, o que proporciona um aprendizado prazeroso e significativo.

As sucatas mais utilizadas são encontradas nos descartes eletrônicos que fornecem para a parte eletrônica resistores, leds, fios, motores e etc, obtidos em impressoras, mouses, brinquedos, e outros equipamentos facilmente encontrados. Madeiras do tipo compensado, telas de arame, tintas, placas de acrílico também compõem o leque de materiais que podem ser aproveitados na construção de um projeto de mecatrônica. A Figura 1 apresenta um projeto de ME utilizando acrílico, motores, fios e rodas, facilmente encontrados em descartes eletrônicos. 


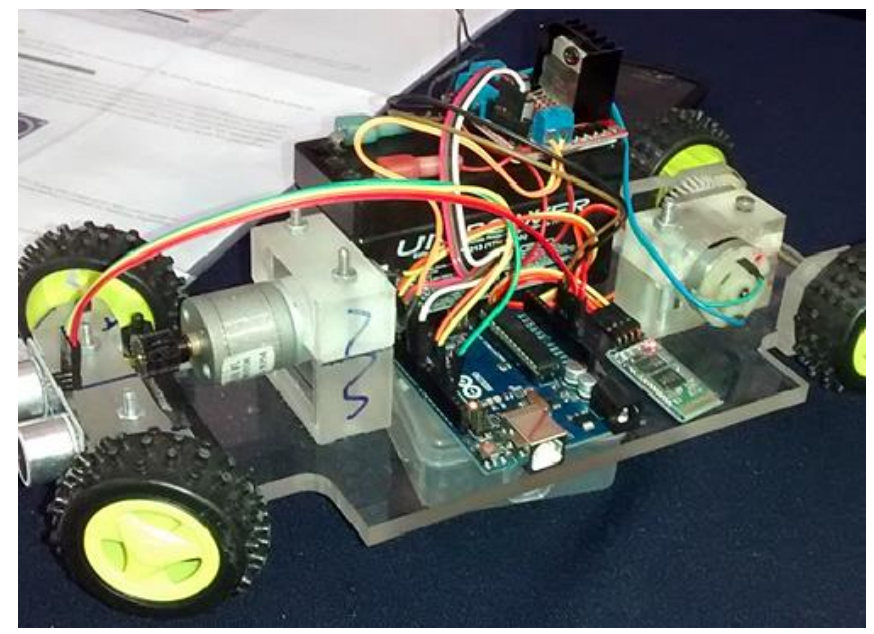

Figura 1 - Carro automatizado feito com sucatas

Como recurso de programação, para automatizar e alimentar os experimentos realizados, a mecatrônica educacional conta com o suporte de plataformas de hardware livre como o Arduíno (Arduíno, 2015). O Arduíno é uma plataforma de custo acessível, disponível no mercado, concebido para ser um recurso para a criação de protótipos de projetos automatizados que podem se tornar reais. A plataforma é formada por dois componentes: um elemento de hardware que consiste de uma placa eletrônica micro controladora; e um ambiente de programação capaz de se comunicar de forma automática com a placa, via porta USB. Tanto o hardware quanto o software têm a documentação aberta e disponível para qualquer usuário utilizar ou alterar, para qualquer projeto ou propósito (Banzi, 2011).

\section{2 - Aprendizagem Baseada em Problemas}

A metodologia Aprendizagem Baseada em Problemas - ABP (Problem Based Learning - PBL), parte do princípio que o aluno seja o coautor da sua própria aprendizagem, ou seja, a construção do conhecimento não deve ser imposta pelo docente.

$\mathrm{Na} \mathrm{PBL}$, o professor age como um facilitador, propondo problemas e auxiliando os alunos no desenvolvimento das tarefas. Os problemas escolhidos, na medida do possível, devem implicar nos alunos o desenvolvimento de diferentes conceitos relacionados ao currículo escolar. Estes, por sua vez, devem ter a oportunidade de analisar e testar as diferentes vias de acesso até a solução, utilizando diferentes fontes de informação ao seu alcance (Savery e Duffy, 1998).

Dentre os benefícios propiciados pela utilização da ABP, como norteadora do processo de aprendizagem, está o desenvolvimento de diferentes habilidades do aprendiz, necessárias ao alcance de metas parciais que levarão à solução do problema apresentado. Quando o aprendiz ou grupo de aprendizes chega à solução geral, desenvolvem atitudes que os permitem adquirir uma ou mais competências relacionadas ao contexto estudado (Costa et al, 2007).

\section{Projeto proposto}

A Mecatrônica Educacional tem sido um potencial instrumento para motivar e envolver alunos no estudo de conceitos de ciências. O esforço do educando é empregado na criação de soluções, sejam essas compostas por hardware e/ou software. As soluções 
visam à resolução de um problema proposto, podendo o mesmo ser do cotidiano, promovendo assim a transformação do ambiente escolar em uma oficina de inventores (Alves, Sampaio e Elia, 2014).

A primeira etapa no processo de construção de um projeto é o planejamento, fundamental para a sua execução e consequente conclusão. Nesta fase, é essencial o desenho (design) do projeto, a definição dos objetivos principais e de quais serão os principais elementos, apontamento de quais questões ou problemas que deverão ser respondidos, e pesquisa de modelos reais representáveis e demais referências para suporte teórico e prático da atividade. Após o planejamento, o trabalho tem como objetivo definir quais serão os objetos e ferramentas necessárias para a montagem dos modelos (Zanetti et al, 2012).

No caso particular deste trabalho o problema proposto como projeto de Mecatrônica Educacional foi um modelo de "estacionamento automatizado".

O trabalho foi realizado com um grupo de alunos do $1^{\circ}$ ano do ensino médio de uma escola particular de classe média na cidade do Rio de Janeiro. Os estudantes tinham idade entre 15 e 16 anos, perfazendo um total de 7 participantes. Os encontros semanais de 3 horas, durou cerca de 4 meses. Todos os recursos necessários para a execução do projeto foram providenciados pela instituição de ensino.

Os passos executados estão apresentados esquematicamente na Figura 2 e detalhados nas próximas seções.

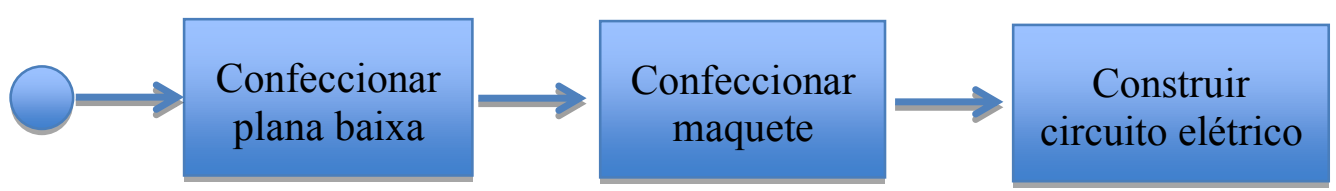

Figura 2 - Passos realizados durante a construção do projeto

\subsection{A confecção de uma planta baixa}

Foi concebida com os alunos uma planta baixa de um modelo de estacionamento automatizado. A Figura 3 ilustra essa planta, aonde é possível observar as dimensões do empreendimento, os elementos que o compõe tais como cancelas automatizadas, iluminação e indicadores luminosos de vagas livres. A partir deste modelo foi elaborada uma lista de materiais que seriam necessários para se por em prática a construção da maquete.

Este foi o ponto de partida para a discussão e consequente aprendizagem de conceitos de matemática, pois ao se conceber a planta baixa de uma maquete, os alunos precisaram aplicar, dentre outros temas, assuntos de geometria plana (razão, proporção, escala), sendo os conteúdos trabalhados de acordo com a necessidade de cada etapa de construção. 
CBIE-LACLO 2015

Anais do XXI Workshop de Informática na Escola (WIE 2015)

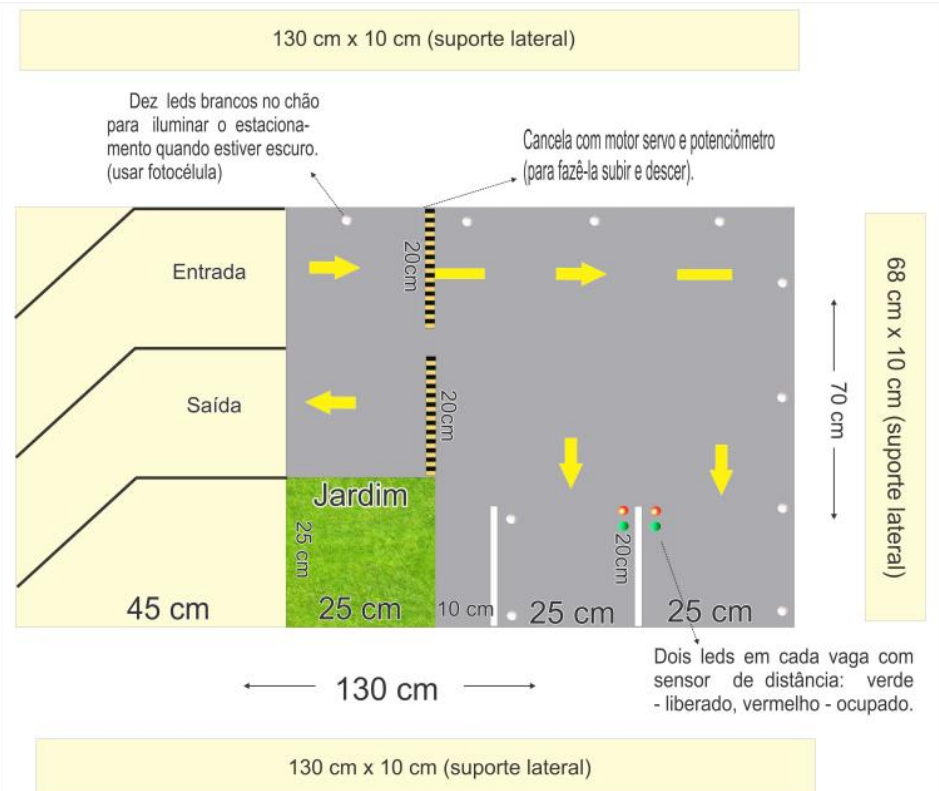

Figura 3 - Planta baixa do projeto "estacionamento automatizado"

\subsection{A confecção de uma maquete: geometria espacial na prática}

A partir da planta baixa, os alunos foram orientados a construir uma maquete. Aos educandos coube também o planejamento, a construção, programação e automação da maquete. O professor, por sua vez, foi responsável por prover o suporte e facilitar o caminho que seria percorrido pelos alunos, orientando-os em cada fase da construção. A Figura 3 ilustra a maquete construída. Observa-se divergências entre a planta baixa e a maquete, o que mostra que a metodologia PBL dá liberdade ao educando para, no decorrer da construção do projeto, realizar alterações que julgue necessárias.

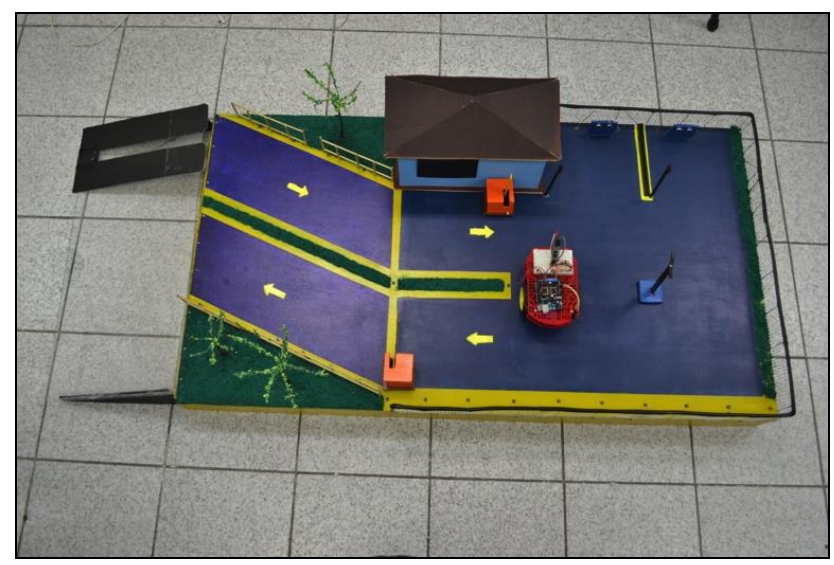

Figura 4 - Maquete do projeto "estacionamento automatizado"

Para a base do projeto (a estrutura do estacionamento), foi proposta a construção de um paralelepípedo de compensado, cujas dimensões dadas deveriam ser respeitadas de modo que as peças de madeira se encaixassem. Além disso, os elementos da maquete (carro, casa, árvores, tela de proteção) e demais componentes da construção deveriam respeitar uma proporção que os harmonizasse. Assim, os carros não poderiam ser 
maiores que a casa, a cancela não poderia ser maior que o poste, as passagens e vagas deveriam respeitar as dimensões dos carros. Conceitos matemáticos foram importantes na execução da estrutura do projeto, pois uma maquete é essencialmente formada por sólidos geométricos, elementos de geometria espacial.

O estudo da Geometria deve possibilitar aos alunos o desenvolvimento da capacidade de resolver problemas práticos do quotidiano, como, por exemplo, orientarse no espaço, ler mapas, estimar e comparar distâncias percorridas, reconhecer propriedades de formas geométricas básicas, saber usar diferentes unidades de medida (MEC, 2015). Esta definição nos dá a certeza de que ela se encontra no dia a dia de todos os estudantes: comprimento, altura, largura, e o conhecimento dos sólidos geométricos nos são apresentados em situações corriqueiras tais como construções arquitetônicas, embalagens, eletrônicos, brinquedos e etc. Numa aula tradicional, os seus elementos são somente teóricos e muitas vezes permanecem no campo das ideias, porém numa construção de um projeto de mecatrônica a aplicação dos conceitos aprendidos valida o que foi estudado.

\subsection{A construção de um circuito elétrico}

A automatização, base da mecatrônica, necessita de elementos mecânicos, eletrônicos, elétricos e a programação de computador. Ao se construir um estacionamento, como uma proposta de ser um modelo de empreendimento, o aluno deveria fazer uma maquete com as mesmas características dos modernos estacionamentos de shoppings e supermercados, que indicam a quantidade de vagas disponíveis e mostram, com códigos de cores intuitivos, se a vaga está disponível (verde) ou ocupada (vermelha).

Como foi utilizado corrente alternada de $110 \mathrm{~V}$ para alimentar o circuito e o Arduíno, os LEDs e demais componentes utilizam corrente contínua, os alunos foram levados a realizar pesquisas sobre o uso de conversor AC/DC, além da lei de Ohm, resistores e seu código de cores. O projeto também utilizou potenciômetros, os sensores LDR, ultrassom, display e motores servo, onde a voltagem de cada um destes elementos necessitava ser respeitada.

\section{Avaliação da aprendizagem}

Para a avaliação da proposta foi utilizado um estudo de caso com avaliação através de questionário final.

O questionário contou com questões envolvendo os conteúdos de matemática e física abordados no projeto (inéditos para alunos do $1^{\circ}$ ano do ensino médio: geometria espacial e eletricidade são usualmente apresentados nos $2^{\circ}$ e $3^{\circ}$ anos do mesmo segmento, respectivamente).

Com a argumentação de que seria uma pesquisa para se concluir o que se aprendeu, os alunos envolvidos no projeto foram convidados a responder as perguntas apresentadas no Quadro 1.

O questionário visou constatar a aprendizagem adquirida através da prática e de observações feitas pelo professor orientador na medida em que o projeto avançava. Ao longo de 4 meses os alunos trabalharam no projeto e buscaram, em cada etapa da construção, aprender novos conceitos para que pudessem enriquecer a proposta elaborada pelo grupo. 
01. A base do nosso estacionamento foi construída com madeira tipo compensado. Sua forma é uma figura espacial denominada: (geometria espacial)
(a) cone
(b) paralelepípedo
(c) cubo

02. Um arduíno fornece $5 \mathrm{~V}$ de tensão para um circuito onde encontra-se um led que necessita de 2 $\checkmark$ de tensão e 0,02 A de corrente para acender.

De modo que o led funcione corretamente, necessitamos incluir no circuito: (eletricidade)
(a) um resistor
(b) um capacitor
(c) um transistor

03. Maquete é uma representação em escala reduzida de grandes estruturas de engenharia ou arquitetura. Entre o real e uma representação, a escala descreve uma : (geometria plana e espacial)
(a) simetria
(b) projeção
(c) proporção

04. Nas fontes que transformam corrente alternada em corrente contínua, existem dois dados que são importantes na alimentação de um equipamento. São eles: amperagem e... (eletricidade)
(a) capacitância
(b) voltagem
(c) resistência

05. Dentre as imagens abaixo, identifique o transistor: (eletrônica)

(a)

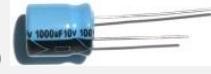

(b)

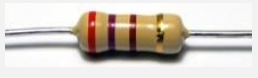

(c)

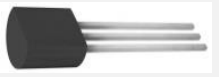

Quadro 1 - Avaliação realizada com os alunos envolvidos no projeto.

Uma análise das respostas dadas pelos alunos sobre alguns conceitos novos em matemática e física permite-nos afirmar que eles desenvolveram um entendimento inicial sobre os mesmos. Entretanto, na única questão sobre eletrônica, incluída com o intuito de saber se haveria o seu reconhecimento, percebemos que de uma maneira geral os alunos não obtiveram um bom resultado. Como o tópico não foi tratado como relevante durante o desenvolvimento do projeto, concluímos que este fato não afetou o objetivo proposto (Quadro 2).

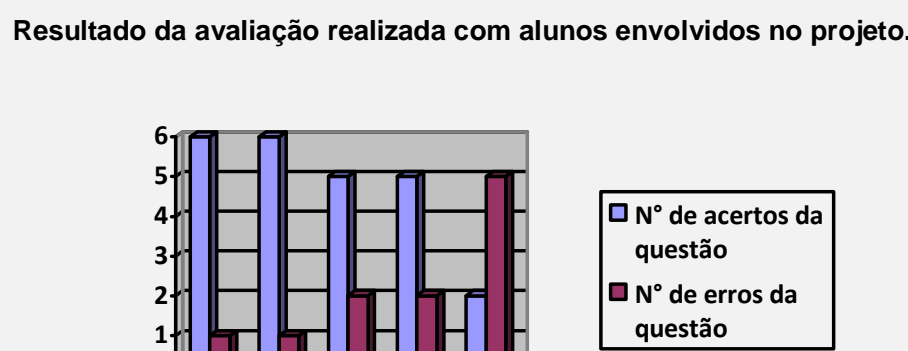

$\square \mathrm{N}^{\circ}$ de acertos da questão

$\square \mathrm{N}^{\circ}$ de erros da questão

\section{Quadro 2 - Resultado da avaliação realizada com os alunos envolvidos no projeto}

As observações feitas pelo professor sobre a participação dos alunos em sala (comentários, intervenções, atitudes tomadas), permite-nos constatar um crescimento pessoal dos alunos envolvidos no projeto, sendo que alguns se destacaram como verdadeiros líderes. 


\section{Conclusões}

Neste trabalho apresentamos a Aprendizagem Baseada em Problemas (ABP) para a condução de um projeto de Mecatrônica Educacional numa escola particular na cidade do Rio de Janeiro. A ABP foi utilizada como instrumento de aprendizagem a partir de um problema proposto, de modo a proporcionar a motivação do educando.

Segundo Latham e Pinder (2005) a motivação é um processo psicológico que resulta da interação do indivíduo com o ambiente.

Quando o sujeito é afetado positivamente por algo, a região responsável pelos centros de prazer produz uma substância chamada dopamina. A ativação desses centros gera bem-estar, que mobiliza a atenção da pessoa e reforça o comportamento dela em relação ao objeto que a afetou (Revista Escola, 2015).

Observamos que a metodologia adotada para o desenvolvimento do projeto com foco na problematização e contextualização - foi fundamental para a obtenção dos resultados positivos obtidos ao final do trabalho. Entre outros aspectos, observou-se que o projeto proposto proporcionou o engajamento dos alunos e o desenvolvimento de conceitos associados a disciplinas do currículo de ciências e matemática.

Numa fase seguinte do projeto pretendemos trabalhar com os alunos numa evolução do projeto, propondo o seguinte desafio: " $O$ que podemos melhorar neste estacionamento para que idosos e pessoas com necessidades especiais possam ter as suas vidas facilitadas?". A partir deste novo problema, novas oportunidades de se trabalhar conceitos em física e matemática surgirão: trigonometria no triângulo retângulo através do uso de rampas e forças aplicadas a uma cadeira de rodas. O tema permitirá ainda a promoção de discussões sobre acessibilidade e o que pode ser feito para facilitar a vida daqueles que possuem necessidades especiais.

\section{Agradecimentos}

Agradecemos à Escola Modelar Cambaúba - RJ pelo investimento e todo incentivo dado às pesquisas com Mecatrônica Educacional, contribuindo de maneira significativa para o avanço do projeto.

\section{Referências}

Alves, R. F.; Sampaio, F. F.; Elia, M. F. DuinoBlocks: Desenho e Implementação de um Ambiente de Programação Visual para Robótica Educacional. Revista Brasileira de Informática na Educação, Volume 22, Número 13, - RBIE, 2014.

Arduíno. http://arduino.cc. Acessado em: abril: 2015

Banzi, M. Primeiros passos com o Arduino. São Paulo: Novatec Editora, 2011. 151 p.

Costa, I. C.; Brandão, A. L.; Musa, D. L.; Teixeira, J.; Sá, E.; Oliveira, A. R.; Oliveira, J. M. P.; Fernandes, C. T. Desenvolvimento de um curso seguindo a Aprendizagem Baseada em Problemas: um estudo de caso -. In : XIII Workshop sobre Informática na Escola - Rio de Janeiro, RJ - WIE, 2007. 
Latham, G. ; Pinder, C. (2005). Work Motivation Theory and Research at the Dawn of the Twenty - First Century. Annual Review Psychology, p.485-516.

MEC. Orientações curriculares para o ensino médio - Ciências da Natureza, Matemática e suas Tecnologias. In:

http://portal.mec.gov.br/seb/arquivos/pdf/book_volume_02_internet.pdf. Acessado em: maio, 2015

Rosário, J. M. Princípios de mecatrônica. São Paulo: Pearson, 2005.

Revista Escola. In: http://revistaescola.abril.com.br/formacao/neurociencia-como-elaajuda-entender-aprendizagem-691867.shtml?page=2. Acessado em: maio, 2015.

Savery, J. R., Duffy, T. M. (1998). Problem Based Learning: An Instructional Model and Its Constructivist Framework. In: B. G. Wilson, Constructivist learning environments: case studies in instructional design (pp. 135-148). Englewood Cliffs, N.J: Educational Technology Publications.

Zanetti, H. A. P.; Souza, A. L. S. de; d Abreu, J. V. V.;Borgesn, M. A. F. Uso de robótica e jogos digitais como sistema de apoio ao aprendizado. In: Jornada de Atualização em Informação na Educação - JAIE, 2012. 